\title{
Reliability and validity of an individually focused food insecurity access scale for assessing inadequate access to food among pregnant Ugandan women of mixed HIV status
}

\author{
Barnabas K Natamba ${ }^{1,2,3, *}$, Hillary Kilama ${ }^{3}$, Angela Arbach ${ }^{4}$, Jane Achan ${ }^{5}$, \\ Jeffrey K Griffiths ${ }^{6}$ and Sera L Young ${ }^{1}$ \\ 'Division of Nutritional Sciences, Cornell University, 116 Savage Hall, Ithaca, NY 14853, USA: ${ }^{2}$ Department of \\ Public Health, Faculty of Medicine, Gulu University, Gulu, Uganda: ${ }^{3}$ PRENAPS Uganda, Kampala, Uganda: \\ ${ }^{4}$ Weill Cornell Medical College, Cornell University, New York, NY, USA: ${ }^{5}$ Department of Pediatrics and Child \\ Health, Makerere University, Kampala, Uganda: ${ }^{6}$ Department of Public Health and Community Medicine, School of \\ Medicine, Veterinary Medicine, Nutrition and Engineering, Tufts University, Boston, MA, USA
}

Submitted 19 December 2013: Final revision received 14 May 2014: Accepted 25 June 2014: First published online 29 August 2014

\begin{abstract}
Objective: To determine the reliability, validity and correlates of measures of food insecurity (FI) obtained using an individually focused food insecurity access scale (IFIAS) among pregnant women of mixed HIV status in northern Uganda.

Design: A mixed-methods study involving cognitive interviews nested within a cross-sectional survey.

Setting: The antenatal care clinic of Gulu Regional Referral Hospital.

Subjects: Survey respondents included 403 pregnant women, recruited in a ratio of one HIV-infected to two HIV-uninfected respondents, twenty-six (nine of them HIV-infected) of whom were asked to participate in the cognitive interviews.

Results: Over $80 \%$ of cognitive interview participants reported understanding the respective meanings of six of the nine items (i.e. items 4 to 9) on the IFIAS. Two main factors emerged from rotated exploratory factor analysis of the IFIAS: mild to moderate FI (IFIAS items 1-6) and severe FI (items 7-9). Together, they explained $90 \cdot 4 \%$ of the FI measure's variance. The full IFIAS and the two subscales had moderate to high internal consistency (Cronbach's $\alpha$ ranged from 0.75 to 0.87 ). Dose-response associations between IFIAS scores, and measures of socioeconomic status and women's diet quality, were observed. Multivariate linear regression revealed significant positive associations between IFIAS scores and HIV infection, maternal age, number of children and a history of internal displacement. IFIAS scores were negatively associated with women's diet diversity score, asset index and being employed.

Conclusions: The IFIAS showed strong reliability, validity and contextual relevance among women attending antenatal care in northern Uganda.
\end{abstract}

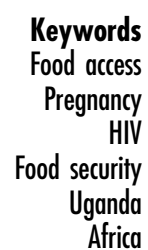

Food security occurs 'when all people, at all times, have physical, social, and economic access to sufficient, safe, and nutritious food that meets their dietary needs and food preferences for an active and healthy life $e^{(1)}$. Food insecurity (FI) exists when these conditions are not met and is a major underlying cause of undernutrition enshrined in the UNICEF conceptual framework ${ }^{(1,2)}$.

FI is a major risk factor for adverse health outcomes among specific vulnerable populations including persons infected with HIV $^{(3,4)}$, women ${ }^{(5)}$ and children ${ }^{(5,6)}$. Women's responsibilities in managing family feeding ${ }^{(7)}$, gender bias in the experience of $\mathrm{FI}^{(8)}$ and unequal control over household resources make them particularly vulnerable to FI and its consequences $^{(3)}$. Data from the USA indicate that, when faced with FI, women suffer a range of negative nutritional ${ }^{(9)}$ and psychosocial consequences ${ }^{(10,11)}$.

Pregnant women are more likely to experience greater FI than non-pregnant women because they have higher nutrient demands, less physical ability to obtain and prepare food (especially later in pregnancy and early postpartum) and less ability to engage in income-generating labour ${ }^{(10)}$. The three studies to date about FI among pregnant women have shown that FI has serious negative nutritional and psychosocial impacts on women's health ${ }^{(9-11)}$. However, all of these studies were done in the USA and contextual differences between resource-rich and 
resource-poor settings make the generalizability of these findings questionable. For instance, a higher burden of infectious diseases and poverty in resource-poor settings may exacerbate women's experiences of FI. Thus, it is important to document the burden and impacts of FI among pregnant women living in resource-poor settings.

The first step to understanding the consequences of FI is to be able to appropriately measure the FI construct. Measures of food security tend to focus on three important and hierarchical domains: availability, access and utilization of food ${ }^{(12)}$. Whereas measures of food availability (e.g. food stocks at national, community and household levels) and utilization (e.g. through assessment of nutritional status) are much easier to ascertain, measuring food access has been more difficult.

There is an increasing focus on assessing the access domain of FI given the emerging psychosocial impacts of FI. Approaches to measuring food access have included both indirect and direct methods ${ }^{(13)}$. Indirect methods of measuring food access tend to focus on proxy measures such as household income and expenditures, dietary diversity or other livelihood strategies. In contrast, direct, experiencebased measures tend to rely on individuals' and families' behaviours and past experiences of FI using questionnaires ${ }^{(13)}$. The Household Food Insecurity Access Scale (HFIAS) ${ }^{(14)}$ is perhaps the most frequently used experiencebased measure of food access. The HFIAS consists of nine questions, each of which has four response options $(\mathrm{no}=0$, rarely $=1$, sometimes $=2$, often $=3$ ). An overall HFIAS score can therefore be derived, with total scores ranging from 0 to 27, with higher scores reflecting more severe FI.

Existing scales for assessing food access, such as the HFIAS, focus on household FI. However, intra-household differences in the experience of $\mathrm{FI}^{(8,15)}$ suggest that food access should also be assessed at the individual level. For this reason, we explored the reliability and validity of a modified HFIAS questionnaire, in which we focused on respondents' individual experiences, rather than asking about those of the entire household. The resultant scale is an individually focused FI access scale, or the IFIAS.

It is recommended that measures of FI be validated through qualitative $e^{(14,16)}$ and quantitative approaches ${ }^{(17,18)}$ so as to ensure their appropriateness. Although the HFIAS has been used and validated to assess FI in a number of countries $^{(13)}$, we did not find any study that had adapted and/or validated this scale to assess individual-level FI. Therefore, to ensure that FI access measures obtained using the IFIAS are reliable, valid and reflect specific contextual factors, we collected qualitative and quantitative data from pregnant women participating in the Prenatal Nutrition and Psychosocial Health Outcomes (PreNAPs) study.

\section{Materials and methods}

Data were collected in the context of the PreNAPs study, a longitudinal observational study designed to document the relationships between food access, nutritional and psychosocial exposures and a number of physical and mental health outcomes among HIV-infected and uninfected pregnant women in post-conflict northern Uganda. Data were collected between 10 October 2012 and 29 August 2013 at the antenatal care clinic of Gulu Regional Referral Hospital (GRRH) in Gulu, northern Uganda. The antenatal care clinic of GRRH is a busy primary care clinic, attending to approximately 400 newly pregnant women on a monthly basis. All services at GRRH, including medications, are offered free of charge, as they are in other public hospitals and clinics in Uganda.

\section{Population}

Women were invited to participate in the PreNAPs study if they were between 10 and 26 weeks' gestation, lived within $30 \mathrm{~km}$ of GRRH and had a known HIV status. Women whose HIV status was unknown were excluded. HIV-infected women were oversampled to achieve a ratio of one HIV-infected to two HIV-uninfected participants; and thus the proportion of HIV-infected women in our sample is much higher than the $10 \cdot 3 \%$ age-adjusted prevalence of HIV observed at various antenatal care clinics in northern Uganda ${ }^{(19)}$.

\section{Study design}

We used a mixed-methods approach to validate the IFIAS. Prior to administration, questionnaires were adapted for use with our specific study population (e.g. by changing the HFIAS into the IFIAS) and translated into Acholi and Langi, the two dominant Luo languages in the area, and then back-translated into English by three Acholi/ Langi-speaking key informants. These included a medical psychiatrist working for GRRH, a study nutritionist and a midwife. Discrepancies in conceptual and semantic equivalence were resolved through discussions. The research team discussed all translated versions and adaptation of the questionnaires until final versions of the questionnaires were agreed upon.

\section{Qualitative validation of the IFIAS}

We conducted qualitative cognitive interviews with a subset of cohort participants to ensure the appropriateness of the IFIAS questions ( $n$ 26). As in the main study sample, about one-third $(34.6 \%)$ of the cognitive interview participants were $\mathrm{HIV}$-infected. Cognitive interviewing is a methodology used to evaluate sources of error/improve quality of survey instruments ${ }^{(20)}$ that has been used successfully to understand respondents' experiences with the Radimer/Cornell FI questions ${ }^{(16)}$. Cognitive interviews were oriented around the nine IFIAS questions. Specifically, we used cognitive testing methods to assess:

1. Comprehension of questions, i.e. to determine whether respondents perceived the intent of IFIAS questions as intended. 
2. Retrieval from memory information relevant to the questions, i.e. to determine whether respondents were able to repeat questions we had asked them and the thought processes they went through to come up with a response to the question.

3. Response process, i.e. to assess whether the response options are appropriate and/or adequate.

Cognitive interviews were conducted by an Acholispeaking study nutritionist (H.K.).

\section{Quantitative validation of the IFIAS}

We also validated the IFIAS quantitatively among the entire study cohort ( $n$ 403). Because there is no 'gold standard' for measuring FI access, we employed approaches that involve establishing construct rather than criterion validity of the IFIAS (Table 1). Construct validity is defined as the extent to which a given measurement corresponds to theoretical concepts (constructs) concerning the phenomena under study, while criterion validity is the extent to which measurements obtained using a new scale concur with those determined with an established diagnostic test or gold standard ${ }^{(21)}$. Construct validity is further divided into convergent and discriminant validity ${ }^{(22)}$. Whereas convergent validity looks at establishing whether a given test measure or outcome is not correlated with concepts or constructs one would expect it to be related with, the goal of discriminant validity is to demonstrate that a given test measure or outcome is not correlated with concepts or constructs that are generally considered to be unrelated to it. Discriminant validity has been erroneously referred to as divergent validity ${ }^{(22)}$. In the current study, we assessed the convergent validity of the IFIAS using a number of measurements (Table 1).

\section{Survey data collection}

At enrolment into the cohort study, trained interviewers administered a questionnaire lasting approximately $45 \mathrm{~min}$.

Table 1 Definitions of terms conceptually important for testing the reliability and validity of measurement scales

\begin{tabular}{|c|c|c|c|}
\hline Term & Definition & Reference & Measurement in this study \\
\hline Internal validity & $\begin{array}{l}\text { The degree to which a study is free from bias or } \\
\text { systematic error. It also refers to the soundness } \\
\text { of the study design, conduct and analysis in } \\
\text { answering the question that is posed for the } \\
\text { study participants }\end{array}$ & 21 & $\begin{array}{l}\text { By providing a comprehensive description of } \\
\text { the study design, data collection and } \\
\text { analysis }\end{array}$ \\
\hline External validity & $\begin{array}{l}\text { The degree to which results of a study may apply, } \\
\text { be relevant or be generalized to populations or } \\
\text { groups that did not participate in the study. } \\
\text { A study is said to be externally valid or } \\
\text { generalizable if it allows unbiased inferences } \\
\text { regarding some other specific target population } \\
\text { beyond the subjects in the study }\end{array}$ & & \\
\hline Criterion validity & $\begin{array}{l}\text { The extent to which measurements obtained } \\
\text { using a new scale concur with those } \\
\text { determined with an established diagnostic test } \\
\text { or gold standard }\end{array}$ & 21 & $\begin{array}{l}\text { As there is no gold standard measure of food } \\
\text { insecurity, in this study we focused instead } \\
\text { on establishing the construct validity of } \\
\text { measurements obtained with the IFIAS }\end{array}$ \\
\hline Construct validity & $\begin{array}{l}\text { A construct is a psychological process or } \\
\text { characteristic believed to account for individual } \\
\text { or group differences in behavior. Construct } \\
\text { validity, therefore, is the extent to which a } \\
\text { measure assesses the construct it purports to } \\
\text { measure }\end{array}$ & 22 & $\begin{array}{l}\text { See Tables } 4,5 \text { and } 6 \text { and Figs } 3 \text { and } 4 \\
\text { We demonstrate strong convergent validity } \\
\text { of the IFIAS in Tables } 4-6 \text { and Fig. } 4 \text {; we } \\
\text { did not explore the discriminant validity of } \\
\text { the IFIAS since we believe that is outside } \\
\text { the scope of this paper }\end{array}$ \\
\hline $\begin{array}{l}\text { Convergent and } \\
\text { discriminant validity }\end{array}$ & $\begin{array}{l}\text { Construct validity encompasses two main types, } \\
\text { i.e. convergent and discriminant validity. } \\
\text { Convergent validity refers to the extent to which } \\
\text { a given measure is correlated with constructs } \\
\text { one would expect it to be related to. On the } \\
\text { other hand, discriminant validity aims to } \\
\text { demonstrate that a given measure is not } \\
\text { correlated with constructs that are generally } \\
\text { considered to be unrelated to it }\end{array}$ & & \\
\hline Reliability & $\begin{array}{l}\text { Reliability is the degree of stability exhibited when } \\
\text { a measurement is repeated under identical } \\
\text { conditions. Similarly, reliability refers to the } \\
\text { extent to which results obtained by a } \\
\text { measurement procedure can be replicated }\end{array}$ & 21 & $\begin{array}{l}\text { In Table 4, we show high Cronbach's a (and } \\
\text { thus internal consistency reliability) values } \\
\text { for the entire IFIAS as well the two } \\
\text { subscales that emerged from exploratory } \\
\text { factor analysis }\end{array}$ \\
\hline $\begin{array}{l}\text { Internal consistency } \\
\text { reliability }\end{array}$ & $\begin{array}{l}\text { Internal consistency reliability, also known as } \\
\text { Cronbach's } a \text {, is an estimate of the correlation } \\
\text { between the total score across a series of items } \\
\text { from a rating scale and the total score that } \\
\text { would have been obtained had a comparable } \\
\text { series of items been employed }\end{array}$ & & \\
\hline
\end{tabular}

IFIAS, individual-level food insecurity access scale. 
Individual-level FI was assessed using the IFIAS. Sociodemographic data collected included maternal characteristics such as age, education, residence, and previous experience with displacement or residence in a camp for internally displaced people (IDP). Wealth was based on the possession of twenty different household assets obtained using the socio-economic module of the 2009-10 Uganda National Panel Survey ${ }^{(23)}$. Health information including gestational age (based on first day of the last menstrual period) and maternal HIV status (determined at the antenatal care clinic prior to enrolment into the PreNAPs study) were also documented. Diet quality was assessed using the women's dietary diversity score (WDDS $)^{(24)}$. The WDDS is based on the sum of nine food groups consumed in the $24 \mathrm{~h}$ preceding the food recall interview. The following set of food groups are recommended for calculating the WDDS: (i) starchy staples; (ii) dark green leafy vegetables; (iii) other vitamin A-rich fruits and vegetables; (iv) other fruits and vegetables; (v) organ meats, meat and fish; (vi) eggs; (vii) legumes; (viii) nuts and seeds; and (ix) milk and milk products.

\section{Data analysis}

Cognitive interviews were transcribed in Acholi and translated into English immediately after each interview. We then looked for common themes and discrepancies in respondents' answers to each question. Understanding of the meanings of items and/or important phrases in each item was then summarized or tallied, as appropriate.

Survey data were entered into EPIDATA $3 \cdot 1$ and analyses were conducted using the statistical software package STATA 12. The IFIAS score and FI categories were based on pregnant women's responses to the nine-item scale, as recommended by Coates et al. for the HFIAS ${ }^{(14)}$. Frequency distributions of responses to all nine IFIAS items were also performed. We derived a wealth index proxy variable, asset index, using the principal component analysis methodology. Per this methodology, households with higher values on the principal component analysis-generated asset index represent greater household wealth relative to others in the sample ${ }^{(25)}$.

The reliability of the IFIAS was assessed using both exploratory factor analysis and Cronbach's test for internal consistency (Table 1). For factor analysis, we used varimaxrotated exploratory factor analysis, retaining factors with eigenvalues above $0 \cdot 5$. We developed subscales using items that consistently grouped together and had factor loadings with values greater than $0 \cdot 45$. The internal consistency of the entire nine-item IFIAS and emergent subscales was assessed using Cronbach's $\alpha$. Cronbach's $\alpha$ coefficients of 0.7 or greater were considered to be reliable ${ }^{(26)}$.

As recommended by Frongillo ${ }^{(17)}$, we tested the parallelism of IFIAS item responses by plotting the proportion of affirmative responses within categories (tertiles) of household asset index. Additionally, we documented the dose-response association between the IFIAS score and indicator variables for socio-economic status and diet quality by assessing how the mean asset index and WDDS varied across quartiles of IFIAS scores.

We determined the convergent validity of the IFIAS using Pearson's correlation coefficients (for exploring how IFIAS was correlated with continuous variables) and $t$ tests (for differences in IFIAS by dichotomous variables). We used non-parametric tests for assessing trends (for categorical variables with more than two categories and assuming ordinal groupings) to compare the performance of the IFIAS scores within categorical measures of education, wealth and diet quality.

Multivariate linear regression was used to examine the independent effects of individual, demographic and socioeconomic characteristics on IFIAS scores. We included variables with $P$ values $\leq 0 \cdot 20$ in bivariate analyses into the multivariate model, but only retained variables with $P$ values $\leq 0.05$ in the final model.

\section{Results}

\section{Participant characteristics}

Of the 415 participants asked to participate in the PreNAPs study, 405 were enrolled (Fig. 1). The ten women who refused enrolment declined, citing 'no time'. Of the 405 , two participants did not complete the entire interview, requesting to come later but never returned, and were excluded from the analysis. Of the 403 remaining participants, $33.0 \%$ ( $n$ 133) were HIV-infected.

Participants selected for the cognitive interview study were similar, but not identical, to the sample in the parent study (Table 2). They were primarily Acholi-speaking Christians, with a mean age of about 25 years and lived with approximately four other people. A greater proportion of cognitive interview participants had less education.

The mean IFIAS score was 9.5 (SD 5.7) for participants in the overall study and 9.3 (SD 5.2) for women participating in the cognitive interviews. Based on the categorization procedure suggested by the authors of the HFIAS ${ }^{(14)}, 74.5 \%$ of respondents in the main survey perceived themselves to be moderately or severely food insecure.

\section{Cognitive interview results}

As one of the first cognitive interview activities, participants were asked to paraphrase the main message of each of the IFIAS items (Table 3). In general, their responses indicated that the items were understood as we had intended. For example, for item 1, we asked respondents what they thought 'enough food' meant. Responses were translated to mean phrases like 'food that is enough for me, my family members, children and visitors' ( $n$ 8) and 'food that satisfies me' ( $n$ 6).

A majority of the respondents ( $>80 \%$ ) in the cognitive interview study were able to appropriately repeat and convey the primary meaning of IFIAS items 4 to 9 (Fig. 2). 


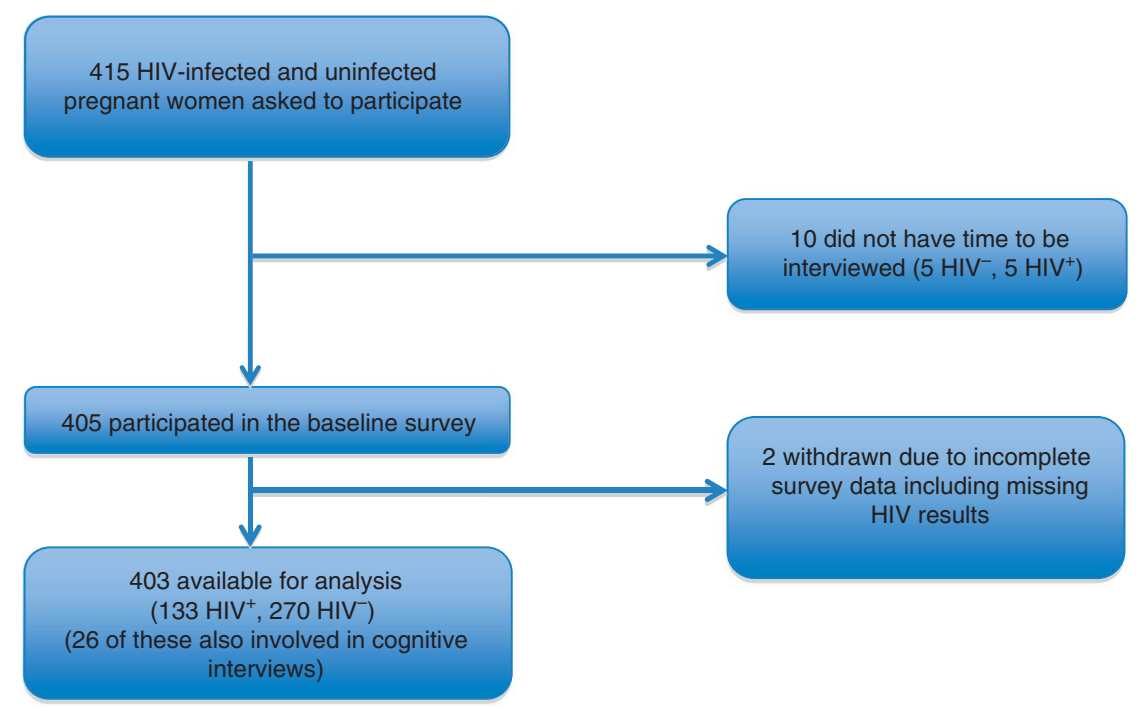

Fig. 1 Diagram of participant flow in the present study

For IFIAS items 1 and 2, the proportion of participants in the cognitive interview study who were able to convey their meaning dropped to slightly below $70 \%$. The most difficult to understand IFIAS item was item 3 (concerning if a respondent had to eat a limited variety of foods due to a lack of resources), with $58 \%$ of cognitive interview participants able to repeat it and provide adequate information with regard to what the item meant.

\section{IFIAS survey results}

Overall, affirmative responses (rarely + sometimes + often) on each of the nine IFIAS items ranged from 16.0 to $87.9 \%$ (Table 4). As expected, responses to IFIAS items indicating less severe FI such as item 2 (not able to eat the kind of foods you preferred) were more prevalent than items indicating more severe FI such as item 9 (going a whole day and night without eating food). Item 2 received the most affirmative responses while item 9 received the least.

\section{Reliability and construct validity}

Two factors emerged from rotated exploratory factor analysis of the IFIAS items. We labelled these as 'mild to moderate FI access' (factor 1) and 'severe FI access' (factor 2). Items 1-6 loaded on to the mild to moderate FI access factor with factor loadings ranging from 0.49 to 0.76 , while items 7-9 loaded on to the severe FI factor with factor loadings ranging from 0.58 to 0.76 . Of all items, item 4 loaded most poorly on to the mild to moderate FI factor with a loading of 0.49 , while item 9 was the poorest to load on the severe FI factor with a loading of 0.58 . The mild to moderate FI factor (items 1-6) explained $75.4 \%$ of the total variance while the severe insecurity factor explained $15.0 \%$ of the variance. The nine-item IFIAS and the two subscales had moderate to high internal consistency. Cronbach's $\alpha$ for the full IFIAS scale was $0 \cdot 87$, 0.86 for the subscale consisting of items $1-6$ and 0.75 for the subscale consisting of items 7-9.
Parallelism across tertiles of bousebold asset index Figure 3 shows the proportion of affirmative responses to each of the nine IFIAS items across tertiles of household asset index. Women in the lowest and middle asset tertiles showed little difference in response to IFIAS items $1-5$, but the proportion of affirmative responses on these items for women in the highest asset tertile was markedly lower. For IFIAS items 6-9, we observed clear parallelism of IFIAS item response curves across the asset index tertiles. Affirmative responses to each of the nine IFIAS items, especially items 6-9, showed clear parallelism across tertiles of women's household asset index.

\section{Dose-response associations}

We observed dose-response associations between severity of FI (represented by the quartile of FI score) and mean (i) household asset index and (ii) WDDS (Fig. 4). Mean asset index and WDDS of the fourth quartile of FI scores was the lowest compared with the first quartile of FI. Unlike the performance of the IFIAS on the parallelism requirement, the overall score on the IFIAS showed a clear-cut doseresponse association with respect to WDDS and asset index variables.

\section{Factors associated with food insecurity}

In bivariate analyses, FI status was significantly and positively associated with maternal age, number of children below 18 years, maternal HIV infection and marital status (i.e. being separated, divorced or widowed; Table 5). Conversely, we observed negative associations between FI and the asset index, formal employment status and WDDS. Contextual factors important for the northern Uganda study setting such as previous history of displacement or stay in an IDP camp were also adversely associated with FI.

In a multivariate linear regression analysis, FI was associated with maternal age, number of children below 18 years, asset index, HIV status, formal employment 
Table 2 Characteristics of pregnant participants in the validation study of the individual-level food insecurity access scale (IFIAS), northern Uganda, October 2012-August 2013

\begin{tabular}{|c|c|c|c|}
\hline Characteristic & Category & $\begin{array}{l}\text { Cognitive interviews } \\
\qquad(n \text { 26) }\end{array}$ & $\begin{array}{l}\text { Survey } \\
(\text { (n 403) }\end{array}$ \\
\hline \multirow[t]{3}{*}{ Language spoken (\%) } & Acholi & $80 \cdot 8$ & $90 \cdot 6$ \\
\hline & Langi & 11.5 & 3.2 \\
\hline & Other & $7 \cdot 7$ & $6 \cdot 2$ \\
\hline \multirow[t]{2}{*}{ Religion (\%) } & Christian & $100 \cdot 0$ & $96 \cdot 5$ \\
\hline & Muslim & 0.0 & 3.5 \\
\hline \multicolumn{4}{|l|}{ Maternal age (years) } \\
\hline Mean & & $25 \cdot 4$ & $24 \cdot 7$ \\
\hline SD & & $4 \cdot 8$ & $5 \cdot 0$ \\
\hline HIV-infected (\%) & & 34.6 & 33.0 \\
\hline \multicolumn{4}{|c|}{ Gestational age at enrolment (weeks) } \\
\hline Mean & & $19 \cdot 9$ & $19 \cdot 3$ \\
\hline SD & & $4 \cdot 1$ & 3.8 \\
\hline \multirow[t]{3}{*}{ Education level (\%) } & Primary or no school & 73.1 & 54.8 \\
\hline & Ordinary level & $23 \cdot 1$ & $32 \cdot 8$ \\
\hline & Advanced level or higher & 3.8 & $12 \cdot 4$ \\
\hline \multicolumn{4}{|l|}{ Household size } \\
\hline Mean & & $4 \cdot 8$ & 4.4 \\
\hline SD & & $2 \cdot 2$ & $2 \cdot 2$ \\
\hline \multicolumn{4}{|c|}{ Number of children in the house below 18 years } \\
\hline Mean & & $2 \cdot 0$ & 1.9 \\
\hline SD & & 1.7 & 1.7 \\
\hline Rural residence (\%) & & $15 \cdot 4$ & $19 \cdot 9$ \\
\hline \multirow[t]{2}{*}{ Occupation (\%) } & Formally employed & 3.8 & 8.4 \\
\hline & Self, informal or unemployed & $96 \cdot 2$ & 91.6 \\
\hline \multirow{3}{*}{ Marital status (\%) } & Single & 11.6 & $6 \cdot 2$ \\
\hline & Married or cohabiting & 88.4 & $86 \cdot 1$ \\
\hline & Separated/divorced/widowed & 0.0 & $7 \cdot 7$ \\
\hline Ever been displaced (\%) & Yes & 61.5 & $72 \cdot 5$ \\
\hline Ever stayed in an IDP camp (\%) & Yes & $50 \cdot 0$ & 51.6 \\
\hline \multicolumn{4}{|l|}{ Household asset index ${ }^{*}$} \\
\hline Median & & 0.09 & 0.23 \\
\hline IQR & & -0.71 to +0.78 & -1.01 to +0.51 \\
\hline \multicolumn{4}{|l|}{ IFIAS score } \\
\hline Mean & & $9 \cdot 3$ & 9.5 \\
\hline SD & & $5 \cdot 2$ & $5 \cdot 7$ \\
\hline \multirow[t]{4}{*}{ IFIAS category $(\%)$} & Food secure & 3.8 & $4 \cdot 2$ \\
\hline & Mildly food insecure & $15 \cdot 4$ & 21.3 \\
\hline & Moderately food insecure & $30 \cdot 8$ & $25 \cdot 6$ \\
\hline & Severely food insecure & $50 \cdot 0$ & $48 \cdot 9$ \\
\hline \multicolumn{4}{|l|}{ WDDS $\ddagger$} \\
\hline Mean & & $4 \cdot 3$ & $4 \cdot 1$ \\
\hline SD & & 1.6 & 1.2 \\
\hline
\end{tabular}

IDP, internally displaced people; IQR, interquartile range; WDDS, women's dietary diversity score.

Data are presented as percentage for categorical variables; or as mean and standard deviation or median and interquartile range for continuous variables. ${ }^{*}$ See Filmer and Pritchett ${ }^{(25)}$ for details on derivation of the asset index.

†Categories constructed based on Coates et al. ${ }^{(14)}$

$\ddagger$ See Kennedy et al. $^{(24)}$ for derivation of the WDDS

status, diet diversity and previous stay in an IDP camp (Table 6). These analyses further confirm the conceptual and contextual relevance of the IFIAS, given that the IFIAS scores were associated with factors expected to be related to them a priori.

\section{Discussion}

In this first mixed-methods validation study of an individually focused FI access scale among pregnant women of mixed HIV status, our data indicate that the IFIAS is an appropriate measure of individual-level FI access. Specifically, most pregnant women understood each of the nine items in the IFIAS (Table 3 and Fig. 2). Further, the output of the IFIAS provided moderate to high reliability (Table 4), strong construct validity (Tables 4-6 and Figs 3 and 4) and fidelity towards conceptual and contextual factors (Tables 5 and 6) associated with FI in the northern Uganda setting. The HFIAS, the original scale from which the IFIAS scale is derived, was designed to be relevant across different contexts and cultures and our results with the IFIAS further affirm that it can be used in a number of settings.

During quantitative validation of the IFIAS, rotated exploratory factor analysis produced two main factors: the mild to moderate FI factor and the severe FI factor. These groupings differed from the three groupings the creators of the HFIAS had proposed ${ }^{(14)}$. Instead of item 1, items 2-4 and items 5-9 on the IFIAS emerging as three different 
Table 3 Participants' interpretations and understanding of the questionnaire items on the individual-level food insecurity access scale (IFIAS) in cognitive interviews ( $n$ 26) among HIV-infected and uninfected pregnant women attending antenatal care services in northern Uganda, October 2012-August 2013

\begin{tabular}{|c|c|c|}
\hline IFIAS item & Primary query in the IFIAS item & Interpretations given by participants \\
\hline 1 & 'Enough food' & $\begin{array}{l}\text { Food that is enough for me, family members, children and visitors ( } n \text { 8) } \\
\text { Food that satisfies me }(n 6) \\
\text { Provides different types in a day }(n 5) \\
\text { Provides at least } 3 \text { meals a day }(n 3) \\
\text { Don't know }(n 4)\end{array}$ \\
\hline 2 & 'Kinds of food you prefer' & $\begin{array}{l}\text { Greens (e.g. boo or malakwang) }(n 8) \\
\text { Beans }(n \text { 6) } \\
\text { Appetizing food }(n 4) \\
\text { Food I desire }(n 3) \\
\text { Food I eat with interest }(n 3) \\
\text { Don't know }(n 2)\end{array}$ \\
\hline 3 & 'Limited variety of foods' & $\begin{array}{l}\text { Only two or one type of food eaten in a day }(n 12) \\
\text { Fewer varieties }(n 8) \\
\text { Small bits of food }(n 3) \\
\text { Don't know }(n 3)\end{array}$ \\
\hline & 'Lack of resources' & $\begin{array}{l}\text { Lack of money }(n 14) \\
\text { Small quantities to no food }(n 6) \\
\text { Other resources that help get food }(n 2) \\
\text { Other resources, e.g. bicycle }(n 1) \\
\text { Don't know }(n 3)\end{array}$ \\
\hline 4 & $\begin{array}{l}\text { 'Eat some foods that you really did not } \\
\text { want to eat' }\end{array}$ & $\begin{array}{l}\text { Food I don't like or desire }(n 11) \\
\text { Beans }(n 3) \\
\text { Cabbage }(n 2) \\
\text { Don't know }(n 6)\end{array}$ \\
\hline 5 & 'Had to eat smaller meal in a day' & $\begin{array}{l}\text { Not eating enough food in terms of quantity }(n 12) \\
\text { Food that was insufficient to satisfy anyone }(n 9) \\
\text { Don't know }(n 5)\end{array}$ \\
\hline 6 & 'Had to eat fewer meals in a day' & $\begin{array}{l}\text { Eating mostly once a day }(n 8) \\
\text { Twice or less than three meals a day ( } n 5) \\
\text { Just fewer meals, non-specific times (5) } \\
\text { Skipping breakfast, lunch or supper }(n 3) \\
\text { Don't know }(n 5)\end{array}$ \\
\hline 7 & 'No food to eat of any kind' & $\begin{array}{l}\text { Lack of food }(n 15) \\
\text { Lack of money to acquire food }(n 8) \\
\text { Lack of other resources to acquire food }(n 3)\end{array}$ \\
\hline 8 & 'Go to sleep hungry at night' & $\begin{array}{l}\text { Slept minus eating anything, no evening meal, ate only during the day }(n 15) \\
\text { Lacked food items in the house to prepare evening meal }(n 5) \\
\text { Don't know }(6)\end{array}$ \\
\hline 9 & 'Went hungry for a whole day and night' & $\begin{array}{l}\text { Never tasting any food for } 24 \mathrm{~h} \text { from morning to night time, both day and } \\
\text { night, full day without eating }(n 17) \\
\text { No food or money }(n 7) \\
\text { I slept hungry }(n 2)\end{array}$ \\
\hline
\end{tabular}

factors as intended with the HFIAS, we observed two new groupings: items 1-6 and items 7-9. This is similar to findings from previous authors' work with item 1 of the HFIAS $^{(27)}$ or of the Radimer/Cornell scale ${ }^{(28)}$, whose wording in both scales is similar. There, neither term emerged as a stand-alone factor in the exploratory factor analyses. However, the inclusion of IFIAS items 5 and 6 together with items $2-4$ in the same grouping is novel to our study. Reports by Mohammadi et al. ${ }^{(29)}$ using data from Iran and by Kneuppel et al. ${ }^{(27)}$ using data from rural Tanzania indicated that item 5 grouped together with HFIAS items 1-4 while item 6 grouped with items 7-9. In the study by Kneuppel et al., the factor loading for item 6 in each of their two emergent factors was above their selected cut-off of $0 \cdot 5$, indicating that potentially HFIAS item 6 can group with HFIAS items 1-5, as was observed in our study.
The loadings that we observed on items 7-9, however, are similar to those described by Deitchler et al. in their analysis of seven data sets involving the HFIAS from six different countries $^{(30)}$. Based on their findings, the authors recommended a three-item scale including items 7, 8 and 9 of the HFIAS, and called it the Household Hunger Scale. The relatively high factor loadings for items 7,8 and 9 into a separate subscale that we observed provides further support for the cross-cultural validity of the Household Hunger Scale.

The reliability coefficients of the full IFIAS and one of the two emergent subscales observed were above the 0.85 cut-off recommended by Frongillo ${ }^{(17)}$ and thus suggested high internal consistency of FI scales (Table 4). Whereas the reliability coefficient of the subscale with items 7-9 was lower than the recommended cut-off, the observed value of 0.75 is also higher than 0.70 , which is a generally accepted cut-off value for internal consistency of measurement 
scales $^{(26)}$. The reliability of the full IFIAS and its subscales was in the same range as what has been reported by previous authors validating FI scales in other sub-Saharan settings ${ }^{(27,28)}$. Kneuppel et al. validated the HFIAS in rural Tanzania and reported Cronbach's $\alpha$ values ranging from $0 \cdot 83$ to $0 \cdot 90$, while Leyna et al. also working in Tanzania with the Radimer/Cornell scale reported values ranging from 0.78 to 0.89 .

The proportion of affirmative responses on each of the nine items on the IFIAS generally followed expected

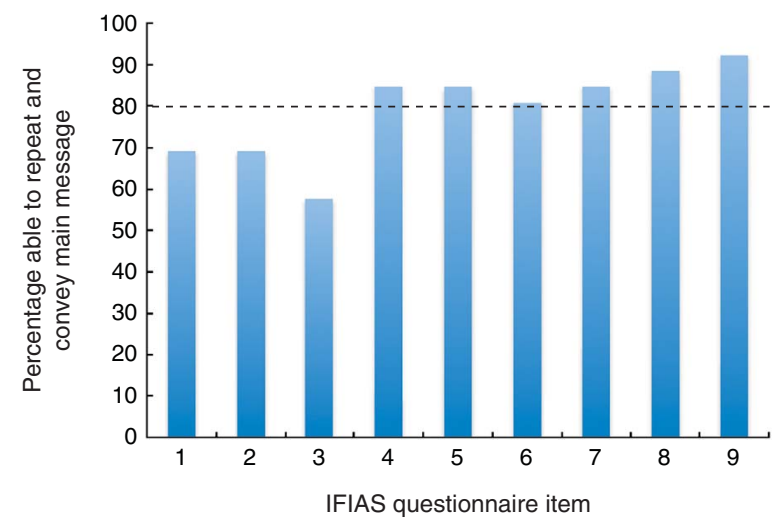

Fig. 2 Proportion of respondents who were able to repeat and convey the main message of each question item of the individual-level food insecurity access scale (IFIAS) among HIV-infected and uninfected pregnant women ( $n$ 26) attending antenatal care clinics in northern Uganda, October 2012August 2013. --- indicates $80 \%$ mark at which cognitive interview participants were able to appropriately repeat and convey the correct meaning of IFIAS items 4-9 patterns, with greater proportions of participants reporting affirmative responses to items indicating moderate (rather than severe) FI (Table 4). The observed trends in affirmative responses, previously reported elsewhere ${ }^{(27)}$, were along an FI severity continuum. However, unlike the initial HFIAS report ${ }^{(14)}$, but consistent with observations from previous studies with the HFIAS ${ }^{(27)}$, we did not find the greatest number of affirmative responses to IFIAS item 1 (Table 4 and Fig. 3). Indeed, IFIAS item response patterns indicate that item 2 had the highest proportion of affirmative responses, followed by item 4 . These results may relate to the possibility that individual and household FI are related but differ. Additionally, this may imply that worrying about food may be perceived differently in different contexts, and/or that actually worrying about food is

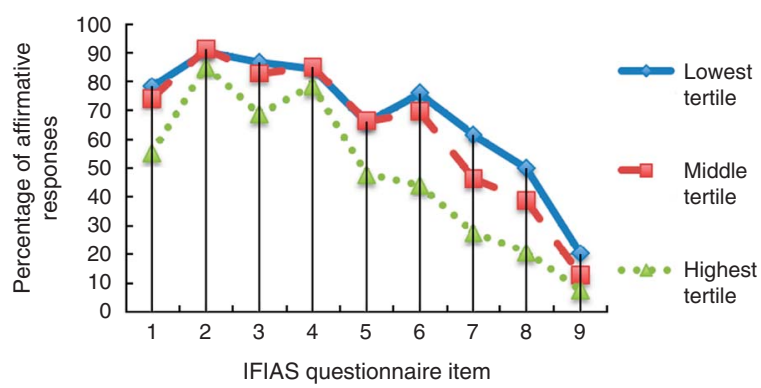

Fig. 3 Item response curves showing proportion of respondents who answered affirmatively to each question item of the individual-level food insecurity access scale (IFIAS) across tertiles of household asset index among HIV-infected and uninfected pregnant women ( $n$ 403) attending antenatal care clinics in northern Uganda, October 2012-August 2013

Table 4 Distribution of affirmative responses to items on the individual-level food insecurity access scale (IFIAS) and varimax-rotated factor loadings of the items among HIV-infected and uninfected pregnant women ( $n$ 403) attending antenatal care services in northern Uganda, October 2012-August 2013

\begin{tabular}{|c|c|c|c|c|}
\hline IFIAS item & $\begin{array}{l}\text { Question: 'In the past four weeks, was there any time } \\
\text { when you...' }\end{array}$ & $\begin{array}{l}\% \text { Yes } \\
\text { responses }\end{array}$ & $\begin{array}{l}\text { Factor } 1 \\
\text { (mild to moderate food } \\
\text { insecurity) loadings }\end{array}$ & $\begin{array}{l}\text { Factor } 2 \\
\text { (severe food insecurity) } \\
\text { loadings }\end{array}$ \\
\hline 1 & '...worried that you would not have enough food?' & $67 \cdot 7$ & 0.680 & \\
\hline 2 & $\begin{array}{l}\text { '...were not able to eat the kinds of foods you preferred } \\
\text { because you couldn't obtain them?' }\end{array}$ & $87 \cdot 9$ & 0.757 & \\
\hline 3 & $\begin{array}{l}\text { '...had to eat a limited variety of foods due to a lack of } \\
\text { resources?' }\end{array}$ & $80 \cdot 8$ & 0.753 & \\
\hline 4 & $\begin{array}{l}\text { '...had to eat some foods that you really did not want to } \\
\text { eat because you couldn't obtain other types of } \\
\text { foods?' }\end{array}$ & $84 \cdot 8$ & 0.495 & \\
\hline 5 & $\begin{array}{l}\text { '...had to eat a smaller meal than you felt you needed } \\
\text { because there was not enough food?' }\end{array}$ & $56 \cdot 6$ & 0.613 & \\
\hline 6 & $\begin{array}{l}\text { '...had to eat fewer meals in a day because there was } \\
\text { not enough food?' }\end{array}$ & $59 \cdot 6$ & 0.691 & \\
\hline 7 & $\begin{array}{l}\text { '...had no food to eat of any kind in your household } \\
\text { because of lack of resources to get food?' }\end{array}$ & $41 \cdot 0$ & & 0.717 \\
\hline 8 & $\begin{array}{l}\text { '...had to go to sleep hungry at night because of food } \\
\text { shortages in the house?' }\end{array}$ & 33.5 & & 0.762 \\
\hline \multirow[t]{4}{*}{9} & $\begin{array}{l}\text { '...went hungry for a whole day and night because of } \\
\text { limited food in the house?' }\end{array}$ & $16 \cdot 0$ & & 0.576 \\
\hline & Eigenvalues for the factor & & $4 \cdot 129$ & 0.819 \\
\hline & Variance explained by the factor (\%) & & $75 \cdot 37$ & 14.95 \\
\hline & Cronbach's $a$ for subscale & & 0.86 & 0.75 \\
\hline
\end{tabular}


unlikely to be as prevalent as, for example, consuming a less diverse diet - a common occurrence in resource-poor settings. It has been reported, for example, that relatively

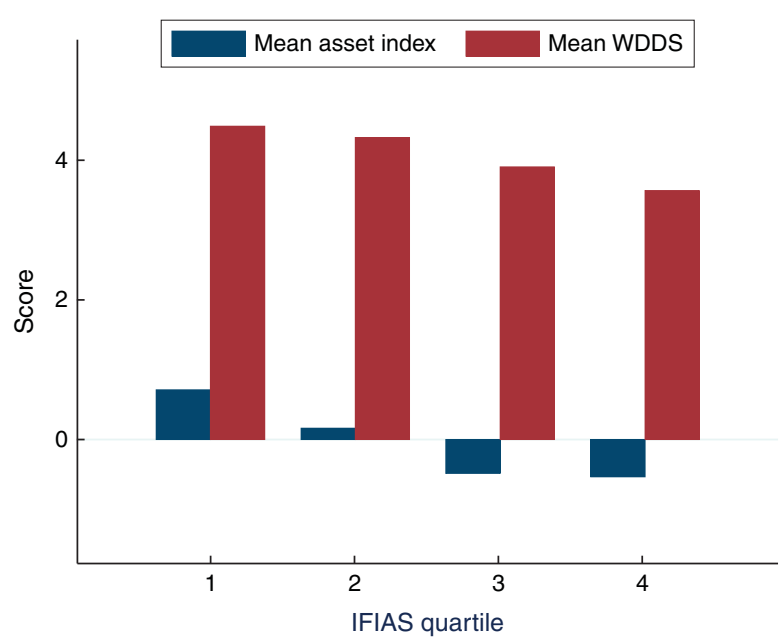

Fig. 4 Dose-response association between mean asset index, women's diet diversity score (WDDS) and quartile of food insecurity access measured by the individual-level food insecurity access scale (IFIAS) among HIV-infected and uninfected pregnant women ( $n$ 403) attending antenatal care clinics in northern Uganda, October 2012-August 2013 more Bangladeshi households affirmed consuming lowerquality food than worried about their food supply ${ }^{(31)}$.

In the absence of a clear-cut 'gold standard' measure of individual-level FI, we relied on establishing other aspects of validity of the IFIAS. We evaluated how measures of FI obtained by the IFIAS stood together as a unified construct or broke into domains or subscales as originally intended by the developers of the HFIAS. We found that the IFIAS broke into two domains (Table 4), rather than the three primary HFIAS domains of being anxious and uncertain about food, relying on a diet of insufficient quality and subsisting on reduced food quantities. However, results from exploratory factor analysis indicated that two domains or subscales emerged with the IFIAS items 1-6 in one domain and items 7-9 in a separate domain. Since this grouping is still consistent with the items' relative importance in establishing FI severity, we believe this outcome is an indication of appropriate construct validity.

It is recommended that measures obtained by FI scales demonstrate parallelism on item response curves and dose-response relationships with respect to economic and diet quality indices ${ }^{(17,18)}$. As Fig. 3 shows, a greater proportion of persons in the lowest tertile of asset index gave affirmative responses to each of the nine IFIAS items compared with those in the highest tertile of asset index. From item 1 through item 5, differences between the

Table 5 Bivariate associations between demographic and socio-economic characteristics and score on the individual-level food insecurity access scale (IFIAS) among HIV-infected and uninfected pregnant women ( $n 403$ ) attending antenatal care services in northern Uganda, October 2012-August 2013

\begin{tabular}{|c|c|c|c|}
\hline Indicator variable & Estimate & Type of statistic & $P$ value \\
\hline Maternal age in years & $0 \cdot 18$ & Pearson's correlation & 0.002 \\
\hline Number of children* & 0.20 & Pearson's correlation & $\leq 0.001$ \\
\hline Marital status ( $1=$ single, $2=$ married or cohabiting, $3=$ separated, divorced or widowed) & $3 \cdot 31$ & $Z$ statistic & 0.001 \\
\hline Ever lived in IDP camp & $5 \cdot 21$ & $t$ statistic & $\leq 0.001$ \\
\hline Asset index† & -0.31 & Pearson's correlation & $\leq 0.001$ \\
\hline Formal employment & -3.89 & $t$ statistic & 0.001 \\
\hline Education level ( $1=$ primary or none, $2=\mathrm{O}$ level, $3=\mathrm{A}$ level or higher) & $-5 \cdot 47$ & $Z$ statistic & $\leq 0.001$ \\
\hline WDDS $\ddagger$ & $-0 \cdot 29$ & Pearson's correlation & $\leq 0.001$ \\
\hline HIV-infected & 4.40 & $t$ statistic & $\leq 0.001$ \\
\hline
\end{tabular}

IDP, internally displaced people; WDDS, women's dietary diversity score.

${ }^{*}$ Children defined as $<18$ years.

†See Filmer and Pritchett ${ }^{(25)}$ for details on derivation of the asset index.

$\ddagger$ See Kennedy et al. ${ }^{(24)}$ for derivation of the WDDS.

Table 6 Final multivariate model of covariates of individual-level food insecurity among HIV-infected and uninfected pregnant women ( $n$ 403) attending antenatal care services in northern Uganda, October 2012-August 2013

\begin{tabular}{lccrr}
\hline Indicator variable & Coefficient & SE & $t$ statistic & $P$ value \\
\hline Maternal age in years & 0.17 & 0.05 & 2.98 & 0.020 \\
Number of children & 0.37 & 0.16 & 2.34 & $\leq 0.001$ \\
Ever lived in IDP camp & 2.06 & 0.50 & 4.11 & $\leq 0.001$ \\
Asset index & -0.69 & 0.16 & -4.23 & $\leq 0.001$ \\
Formal employment & -2.29 & 0.94 & -2.45 & 0.015 \\
WDDS & -0.94 & 0.20 & -4.72 & $\leq 0.001$ \\
HIV-infected & 1.31 & 0.55 & 2.39 & 0.017 \\
Intercept & 7.31 & 1.53 & 4.77 & $\leq 0.001$ \\
\hline
\end{tabular}

IDP, internally displaced people; WDDS, women's dietary diversity score. 
proportions of responses on each IFIAS item between participants within the different asset index tertiles are less dramatic than for items 6-9. As one progresses from item 6 to item 9, clear parallel trends emerge in the proportion of affirmative responses across the tertiles. We did not detect much difference in the perceptions of anxiety and uncertainty about food or limited diet quality, as reflected in IFIAS items 1 through 5, between the poorest and middle tertiles. As one transitions from IFIAS item 6 to item 9, one sees more severe forms of FI including actual reductions in food stocks and greater hunger.

Similar to the observation of parallelism across questionnaire item response curves noted above, we observed dose-response associations between FI measures and mean asset index and WDDS (Fig. 4). This further suggests strong convergent validity with our individually focused FI scale.

Construct validity was further established by assessing the convergence of measures of FI with other demographic, socio-economic and contextual factors expected to be associated with FI. Indeed, bivariate and multivariate analyses indicated that higher FI scores were positively associated with being older, having many children below 18 years, being HIV-infected and having a history of previous stay in an IDP camp (Tables 5 and 6). On the other hand, and as expected, IFIAS measures were negatively associated with higher asset index, being formally employed and WDDS. Others have documented the relationship between FI and respondents' increased age and greater number of children ${ }^{(27,32)}$ and household socio-economic indicators ${ }^{(27)}$ such as household wealth status and the education level of either spouse.

Most of the factors associated with FI in our study are well known to be related to $\mathrm{FI}^{(27,32)}$. We were, however, surprised to find that having ever resided in an IDP camp is significantly associated with FI even several years after the civil war in northern Uganda ended. The IDP camps were closed during the period 2007-2012 with former IDP camp residents often returning to homes and farms that had been neglected for years. Factors contributing to greater perceived individual FI access among former IDP residents need to be investigated so that appropriate interventions can be targeted and implemented.

The strengths of the present study include the use of multiple measures of reliability and validity; comparison of scale performance across a multiplicity of conceptually driven and contextual determinants of FI; and use of a number of statistical tests to assess the utility of the IFIAS as a measure of individual-level FI among HIV-infected and uninfected pregnant women in northern Uganda.

There are also several limitations. In order to conserve resources, we conducted the cognitive interviews concurrently with the main survey; ideally cognitive interviews would have preceded the survey. Thus, we were unable to test modifications of the IFIAS items based on cognitive interview results. The finding from cognitive interviews that IFIAS item 3 was the most difficult to understand is novel to our study, and it might have impacted negatively on our findings. The cross-sectional study design precluded assessment of the stability of FI measures over time. This limitation will be addressed by repeated measures of FI in the PreNAPs cohort. Finally, while our study is designed to have strong internal validity, our cohort does not represent the general pregnant women's population in Gulu or northern Uganda due to the oversampling of HIV-infected women. Our oversampling of HIV-infected women does, however, provide us with insights as to differences in FI between HIV-infected and uninfected women.

\section{Conclusion}

In summary, our study demonstrates strong reliability, internal validity and contextual fidelity of measures of FI obtained using the IFIAS from HIV-infected and uninfected pregnant women. We encourage other researchers to use and validate the IFIAS in other settings and among other populations (e.g. the elderly, lactating women) and to compare scores and prevalence of FI categories obtained with the IFIAS with those obtained using the HFIAS.

\section{Acknowledgements}

Acknowledgements: The authors would like to acknowledge the support of the GRRH administration in allowing them to conduct the study at the hospital's antenatal care clinic and providing space for the research team within the hospital buildings. The authors thank Sophie Becky Ajok, the coordinator for prevention of mother-to-child transmission of HIV services at GRRH antenatal clinic, for helping them recruit pregnant women to the study. They also thank PRENAPS Uganda staff: Stella Adoch, Gladys Acayo, Winifred Achoko, Daniel Acidri and Claire Biribawa, for their dedication and hard work on this study. Lastly, they gratefully acknowledge Rebecca Stoltzfus, Patsy Brannon and Saurabh Mehta for comments on earlier drafts. Financial support: Funding was provided by the US Agency for International Development (USAID) Feed the Future Innovation Laboratory for Collaborative Research in Nutrition for Africa (award number AID-OAA-L-10-00006 to Tufts University). The content of this paper is solely the responsibility of the authors and does not necessarily represent the official views of USAID. S.L.Y. was supported by the National Institute of Mental Health (grant number K01 MH098902). The content is solely the responsibility of the authors and does not necessarily represent the official views of the National Institute of Mental Health or the National Institutes of Health. Conflict of interest: None. Authorship: B.K.N., S.L.Y., J.A. and J.K.G. conceived and designed study. B.K.N., H.K. and A.A. supervised data collection. H.K. conducted cognitive interviews. B.K.N. and S.L.Y. performed all the data analyses. B.K.N. wrote the first draft of the manuscript. All authors contributed to the interpretation of the data, 
revising the manuscript critically for important intellectual content, and approved the final version. Ethics of buman subject participation: Cornell University Institutional Review Board and Gulu University Institutional Review Committee approved the study protocol. The permission to carry out the study in Uganda was granted by the Ugandan National Council for Science and Technology. Written informed consent was sought from all study subjects before they were enrolled into the study.

\section{References}

1. Food and Agriculture Organization of the United Nations (1996) Rome Declaration on World Food Security and World Food Summit Plan of Action. Rome: FAO.

2. UNICEF (1990) Strategy for Improved Nutrition of Children and Women in Developing Countries. New York: UNICEF.

3. Weiser SD, Young SL, Cohen CR et al. (2011) Conceptual framework for understanding the bidirectional links between food insecurity and HIV/AIDS. Am J Clin Nutr 94 1729-1739.

4. Ivers LC, Cullen KA, Freedberg KA et al. (2009) HIV/AIDS, undernutrition, and food insecurity. Clin Infect Dis 49, 1096-1102.

5. Whitaker RC, Phillips SM \& Orzol SM (2006) Food insecurity and the risks of depression and anxiety in mothers and behavior problems in their preschool-aged children. Pediatrics 118, e859-e868.

6. Cook JTJ, Frank DAD, Berkowitz CC et al. (2004) Food insecurity is associated with adverse health outcomes among human infants and toddlers. J Nutr 134, 1432-1438.

7. Olson CM (2005) Food insecurity in women: a recipe for unhealthy trade-offs. Top Clin Nutr 20, 321.

8. Hadley C, Lindstrom D, Tessema F et al. (2008) Gender bias in the food insecurity experience of Ethiopian adolescents. Soc Sci Med 66, 427-438.

9. Laraia BA, Siega-Riz AM \& Gundersen C (2010) Household food insecurity is associated with self-reported pregravid weight status, gestational weight gain, and pregnancy complications. J Am Diet Assoc 110, 692-701.

10. Laraia BA, Siega-Riz AM, Gundersen C et al. (2006) Psychosocial factors and socioeconomic indicators are associated with household food insecurity among pregnant women. J Nutr 136, 177-182.

11. Hromi-Fiedler A, Bermúdez-Millán A, Segura-Pérez S et al. (2011) Household food insecurity is associated with depressive symptoms among low-income pregnant Latinas. Matern Child Nutr 7, 421-430.

12. US Agency for International Development (1992) Policy Determination \#19: Definition of Food Security. Washington, DC: USAID.

13. Jones AD, Ngure FM, Pelto G et al. (2013) What are we assessing when we measure food security? A compendium and review of current metrics. Adv Nutr 4, 481-505.

14. Coates J, Swindale A \& Bilinsky P (2007) Household Food Insecurity Access Scale (HFIAS) for Measurement of Food Access: Indicator Guide. Washington, DC: Food and
Nutrition Technical Assistance (FANTA), Academy for Educational Development.

15. Abdullah M \& Wheeler EF (1985) Seasonal variations, and the intra-household distribution of food in a Bangladeshi village. Am J Clin Nutr 41, 1305-1313.

16. Alaimo K, Olson CM \& Frongillo EA (1999) Importance of cognitive testing for survey items: an example from food security questionnaires. J Nutr Educ 31, 269-275.

17. Frongillo EA (1999) Validation of measures of food insecurity and hunger. J Nutr 129, 2S Suppl., 506S-509S.

18. Pérez-Escamilla R, Segall-Corrêa AM, Kurdian Maranha L et al. (2004) An adapted version of the US Department of Agriculture Food Insecurity Module is a valid tool for assessing household food insecurity in Campinas, Brazil. J Nutr 134, 1923-1928.

19. Fabiani M, Nattabi B, Pierotti C et al. (2007) HIV-1 prevalence and factors associated with infection in the conflict-affected region of North Uganda. Confl Health 1, 3.

20. Willis GB (1994) Cognitive Interviewing and Questionnaire Design: A Training Manual. Hyattsville, MD: US DHHS, CDC, NCHS

21. Porta M (2008) A Dictionary of Epidemiology. New York: Oxford University Press.

22. Strauss ME \& Smith GT (2009) Construct validity: advances in theory and methodology. Annu Rev Clin Psychol 5, 1-25.

23. Uganda Bureau of Statistics (2010) The Uganda National Panel Survey 2009/10: Household Questionnaire. Kampala: UBOS.

24. Kennedy G, Ballard T, Dop MC et al. (2011) Guidelines for Measuring Household and Individual Dietary Diversity. Rome: FAO.

25. Filmer DD \& Pritchett LHL (2001) Estimating wealth effects without expenditure data - or tears: an application to educational enrollments in states of India. Demography 38, 115-132.

26. Santos J (1999) Cronbach's alpha: a tool for assessing the reliability of scales. $J$ Extension 37, issue 2; available at http://www.joe.org/joe/1999april/tt3.php

27. Knueppel D, Demment M \& Kaiser L (2010) Validation of the household food insecurity access scale in rural Tanzania. Public Health Nutr 13, 360-367.

28. Leyna GH, Mmbaga EJ, Mnyika KS et al. (2010) Food insecurity is associated with food consumption patterns and anthropometric measures but not serum micronutrient levels in adults in rural Tanzania. Public Health Nutr 13, 1438-1444.

29. Mohammadi F, Omidvar N, Houshiar Rad A et al. (2012) Validity of an adapted Household Food Insecurity Access Scale in urban households in Iran. Public Health Nutr 15 , 149-157.

30. Deitchler M, Ballard T, Swindale A et al. (2010) Validation of a Measure of Household Hunger for Cross-Cultural Use. Washington, DC: USAID Food and Nutrition Technical Assistance (FANTA).

31. Coates J, Frongillo EA, Rogers BL et al. (2006) Commonalities in the experience of household food insecurity across cultures: what are measures missing? J Nutr 136, issue 5, 1438S-1448S.

32. Nagata JM, Magerenge RO, Young SL et al. (2012) Social determinants, lived experiences, and consequences of household food insecurity among persons living with HIV/ AIDS on the shore of Lake Victoria, Kenya AIDS Care 24, 728-736. 